\title{
Improved Kayaking Ergometer Using a Switch-mode Converter Driven Alternator
}

Cornaby, Chris; Friberg, Jeppe; Søndergaard, Nikolaj B. ; Lindberg-Poulsen, Kristian; Zsurzsan, TiberiuGabriel

\section{Published in:}

Proceedings of 2016 IEEE International Conference on Industrial Technology

Link to article, DOI:

10.1109/ICIT.2016.7474744

Publication date:

2016

Document Version

Peer reviewed version

Link back to DTU Orbit

Citation (APA):

Cornaby, C., Friberg, J., Søndergaard, N. B., Lindberg-Poulsen, K., \& Zsurzsan, T-G. (2016). Improved Kayaking Ergometer Using a Switch-mode Converter Driven Alternator. In Proceedings of 2016 IEEE International Conference on Industrial Technology (pp. 165-169). IEEE.

https://doi.org/10.1109/ICIT.2016.7474744

\section{General rights}

Copyright and moral rights for the publications made accessible in the public portal are retained by the authors and/or other copyright owners and it is a condition of accessing publications that users recognise and abide by the legal requirements associated with these rights.

- Users may download and print one copy of any publication from the public portal for the purpose of private study or research.

- You may not further distribute the material or use it for any profit-making activity or commercial gain

- You may freely distribute the URL identifying the publication in the public portal 


\title{
Improved Kayaking Ergometer Using a Switch-mode Converter Driven Alternator
}

\author{
Chris Cornaby, Jeppe Friberg, Nikolaj B. Søndergaard, Kristian Lindberg-Poulsen, Tiberiu-Gabriel Zsurzsan \\ Institute of Electrical Engineering \\ Technical University of Denmark
}

\begin{abstract}
This paper describes the implementation of a generator as a source of resistance in a modern kayaking ergometer. This ergometer can function as a platform for emulation of the athlete-kayak-paddle system. The system was considered and described. A possible model for digital regulation has also been described. A synchronous-rectified buck converter has been designed to control the current through the rotor and, by extension, the mechanical resistance felt by the oarsman. The circuit was designed to function with a $12 \mathrm{~V}$ car battery as a supply. Necessary specifications for efficiency and output stability were set, measured and met. The prototype without regulation was presented at the 2015 Kayaking World Cup, and was met with appreciation and positive feedback.
\end{abstract}

\section{INTRODUCTION}

Currently indoor rowing machines, known as kayaking ergometers, are being used by professionals and amateurs alike for convenient training. Many different versions of kayaking ergometers exist. The idea of this paper is to replace the ordinary sources of mechanical resistance with an alternator delivering a variable resistance. The issue with a the mechanical approach to the emulation of kayaking, lies in the dynamics of the stroke through water. The drag through the water will initially be high, but as it is broken into laminar flow resistance and turbulent flow resistance, the drag of the water changes through the stroke. This can be emulated more accurately by use of digital regulation and a computer model of the athlete-kayak-paddle system. An overview of the controller circuit is provided along with results on how well the circuit performs.

This paper also discusses potential improvements to the existing system, as the design described in this paper is meant as a platform for further work on advanced emulation of kayaking.

\section{System DyNAMiCS}

The main reason that the traditional ergometers are insufficient is their inability to accurately emulate the dynamics of a athlete-kayak-paddle system. In all modern ergometers the machine is separated from any large bodies of water and the fluid dynamics of water are unsuccessfully recreated.

There are two forces acting on the system in the anteroposterior direction; $F_{P}$, the forward element of the blade force $F_{B}$, also known as the force of propulsion, and $R_{T}$, the total aerodynamic and hydrodynamic drag forces[1]. $\mathrm{M}$ is the total mass of our system.

The equations governing the change of velocity in the anteroposterior direction are:

$$
d v_{x}=\frac{F_{P}+R_{T}}{M} d t
$$

Where the total resistance can be broken down into the aerodynamic and hydrodynamic resistance. The hydrodynamic resistance can further be broken into viscous $\left(R_{V}\right)$ and wave $\left(R_{W}\right)$ resistance[1]. These can be calculated from the coefficient of viscosity $\left(C_{V}\right)$ and wave drag $\left(C_{W}\right)$ as:

$$
\begin{aligned}
R_{V} & =\frac{1}{2} \cdot \rho_{W} \cdot C_{V} \cdot S_{W} \cdot v_{/ W}^{2} \\
R_{W} & =\frac{1}{2} \cdot \rho_{W} \cdot C_{W} \cdot \frac{\sigma}{L} \cdot v_{/ W}^{2}
\end{aligned}
$$

Where $v_{/ W}$ is the hull velocity relative to the water, $\rho_{W}$ the density of water, $S_{W}$ the submerged surface area of the hull, $\sigma$ the maximum sectional area of the hull and $\mathrm{L}$ the length of the waterline[1].

The aerodynamic drag is expressed as:

$$
R_{A}=\frac{1}{2} \cdot \rho_{A} \cdot C_{A} \cdot S_{A} \cdot v_{/ A}^{2}
$$

Where $\rho_{A}$ is the density of air, $C_{A}$ is the aerodynamic drag coefficient, $S_{A}$ is the forward frontal area of the system above water and $v_{/ A}$ is the velocity of the air relative to the system. The estimation of constants is not the subject of this paper.

There are also vertical forces to consider; $\mathrm{B}$, the buoyancy of the kayak and w, the weight of the system. When the kayak is in motion the blade force $F_{B}$ will likely have a vertical component, causing the system to become less submerged the faster it goes. This implies that the surface area of the submerged part of the system will wary with speed and/or stroke technique, something to consider for advanced modelling. These vertical forces will not be considered in the following section, as that would increase the degrees of freedom and complexity of the system considerably while adding very little to the emulation.

\section{REgulator Design}

There are a few things to consider before a regulator can be designed. The "load" felt by the paddle in accelerating the system is proportional to the difference in velocity between 
the paddle and the kayak, assuming that the user is rowing in still water. Due to the string based force transfer method of the mechanical system, we cannot simulate the push of the water on the paddle in those cases where the kayak is moving at a higher velocity than the paddle. Furthermore there is a torque constant relating the force the paddle is acting on the water with and the current magnitude in the rotor of the generator, to correlate the simulated load and the load in the generator. This proportionality factor will be dependent on the generator used. The model of the system and a possible design for the regulator can be seen in Fig. 1. There are two transfer functions in the model. One is for the change in speed of the kayak and should correlate to the inertia of the system. The second is for the simulated load, and should be adjusted to give a correct feeling of a paddle through water. In-depth consideration of these transfer functions will be addressed in future work.

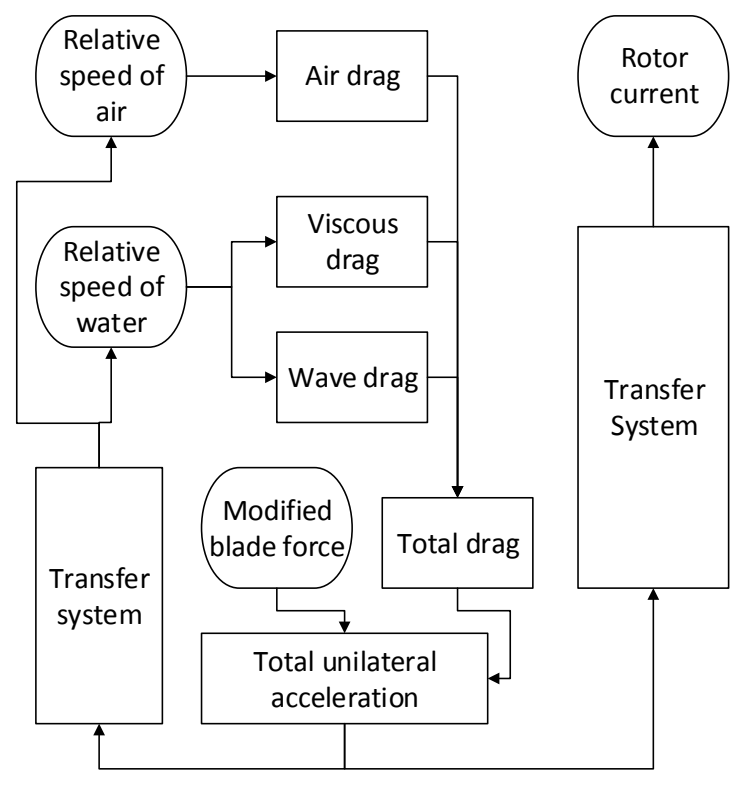

Fig. 1. Block diagram of the system model.

\section{Controller Design}

The control circuit has been designed from a list of initial goals:

- Efficiency should be greater that $85 \%$.

- Maximum output ripple should be less that $10 \%$ at max IOut.

- Passive cooling should keep the circuit below $75^{\circ} \mathrm{C}$

The converter chosen for our control circuit is a synchronous-rectified buck converter. This converter topology has been chosen due to the demand of zero output without shutting down the circuitry. A synchronous rectified version of the buck has been chosen to reduce the losses in the circuit. The alternator winding resistance is estimated to $2 \Omega$.
$12 \mathrm{~V}$ across the windings will result in a $6 \mathrm{~A}$ rotor current when the rotor is not moving. This current is sufficient to produce the required maximum resistance.

When the circuit is turned on, it amplifies the output current and dampens output voltage as a linear function of duty cycle[2]:

$$
\begin{gathered}
I_{\text {out }}=\frac{I_{\text {in }}}{D} \\
V_{\text {out }}=V_{\text {in }} \cdot D
\end{gathered}
$$

The linear nature of this type of converter makes it easy to change the output current $I_{\text {out }}$, and hereby change the magnetic resistance in the alternator. The control circuit is designed with a voltage-controlled pulse width modulator (PWM) that has a controllable duty cycle. The prototype has a manually changeable duty cycle, which is achieved by using a potentiometer in a voltage division to control the input voltage. The PWM signal is used to control a gate driver which then controls the two MOSFETs.

The efficiency of the converter depends on the conduction losses and switching losses. To minimise the conduction losses, the $R_{D S \text { (on) }}$ in the MOSFET's, as well as the resistance in the copper wire of the inductor, should be as low as possible. These losses are reduced primarily by choosing the right components.

The switching losses are a combination of the internal MOSFET loss, and the loss resulting from parasitic inductance due to gate and switching loops.

\section{MEChANICAL IMPLEMENTATION}

A kayaking ergometer was provided with a resistance fan which was replaced with a cogwheel. A smaller cogwheel was mounted on the alternator, and a chain was fitted to the appropriate length, as seen on Fig. 2. The force put into the strokes, also known as the blade force $F_{B}$, is converted into torque, which in turn drives the alternator with a gearing of $1: 1.5$. A low gearing is used to reduce the minimum resistance, so that operation with very low resistance is possible.

\section{A. Alternator Functionality}

As a given specification, an oarsman produces up to $600 \mathrm{~W}$ of continuous power. The alternator acquired is therefore specified to handle at least $1 \mathrm{~kW}$. The alternator used in the prototype is a standard Lundell type car alternator, which requires a current through the rotor to generate the magnetic field required to induce an output. The alternator has been refitted, so that this rotor current is controlled by the controller circuit. The Lundell type alternator is designed to work with a car engine, and generates power in the interval $900-10,000$ RPM[3]. With our gearing of 1:1.5, this requires the user to row a minimum of 600 RPM to generate power as our battery supplies 12V. By Faraday's law:

$$
|\epsilon|=\left|\frac{d \Phi_{B}}{d t}\right|
$$




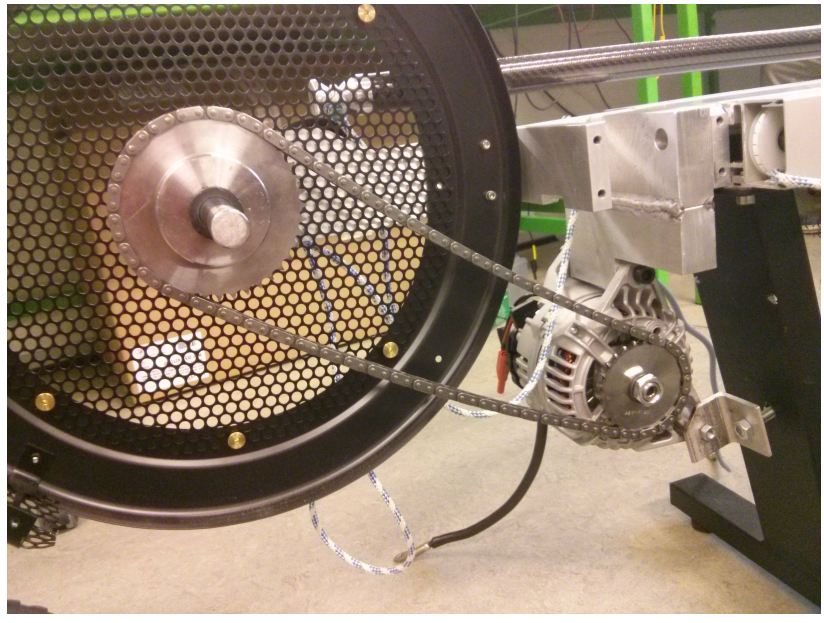

Fig. 2. Ergometer fitted with a cogwheel, alternator and a chain connecting the two

The induced voltage $\epsilon$ is proportional to the change of the magnetic field $\Phi_{B}$ over time. This means that the induced voltage is proportional to both the angular velocity of the rotor and the strength of the magnetic field in the rotor. At a constant velocity and magnetic field strength, the output of the alternator can be measured as a sinusoidal wave. This is then rectified by a full-wave rectifier in the alternator. Fig. 3 shows a simplified version of this circuit.

\section{SENSOR ImPLEMENTATION}

A six axis gyroscope and accelerometer (in a MPU-6050 chip) were fitted at each end of the paddle. In this way we can measure and calculate the kinematics of each blade, and use it as the modified blade force seen in Fig. 1.

IR diodes were fitted at the ends of the paddle and sensors were fitted below the seat of the user, for measuring if the paddle was below the waterline or not. Changing the placement of the sensors decide waterline height in relation to the user. By reading the blade force and waterline sensors into an Arduino UNO, the Arduino calculates the needed load for a given speed of the kayak compared to the momentum of the stroke, and sets the control signal to the power converter, which in turn adjusts the rotor current giving a greater sense of resistance to the rower. The emulation is in this way controlled digitally by the Arduino, where constants and transfer functions can be adjusted to give a better emulation, though this is not the focus of this paper. The complete setup of sensors and Arduino can be seen on Fig. 3 .

\section{MEASUREMENTS}

To further reduce the switching losses, the circuitry has been constructed on a printable circuit board (PCB). The final PCB design can be seen in Fig. 5. In the design, large heat sinks have been included for both of the MOSFETs' drains for better heat dissipation. A thermal picture after two hours of continuous maximum output can be seen on Fig. 4. The greatest temperature is reached by the gate driver at $42,1^{\circ} \mathrm{C}$.

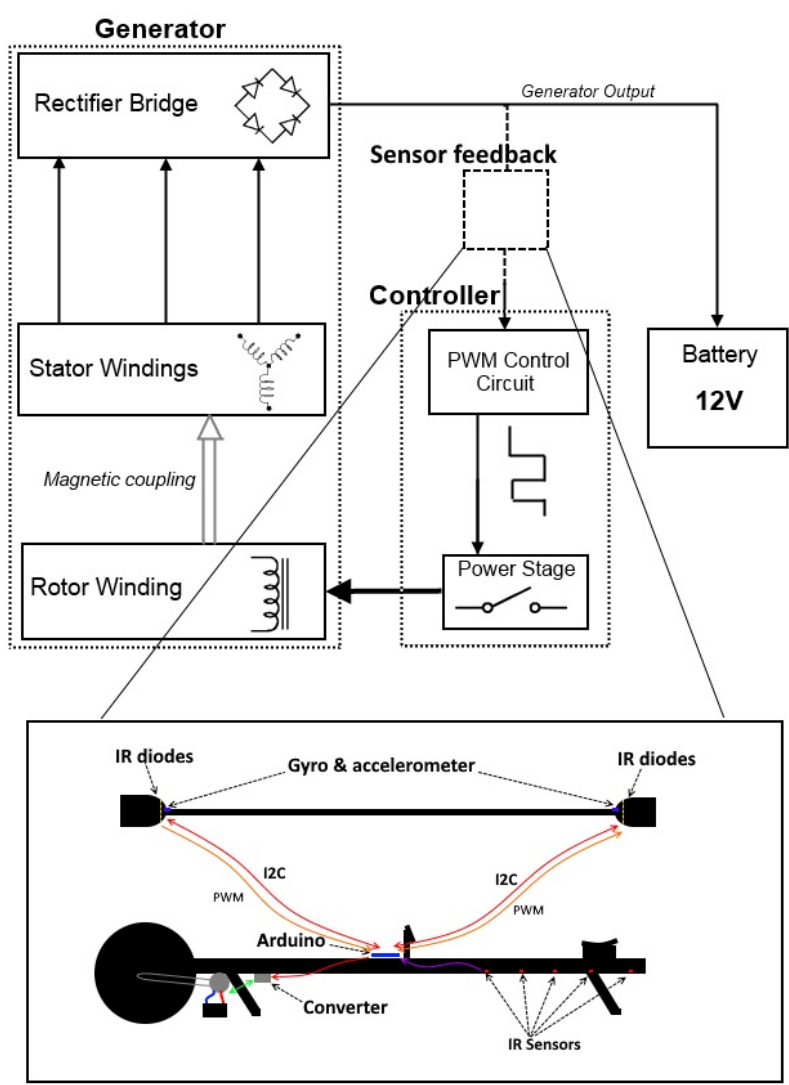

Fig. 3. Complete block diagram showing significant interconnections

The gate driver is rated for an absolute maximum temperature of $150{ }^{\circ} \mathrm{C}$.

Implementing the PCB greatly reduced switching losses due to reduced parasitic inductances from loops. A PCB also reduces conduction losses in the copper wire since the size of the circuit is greatly reduced.

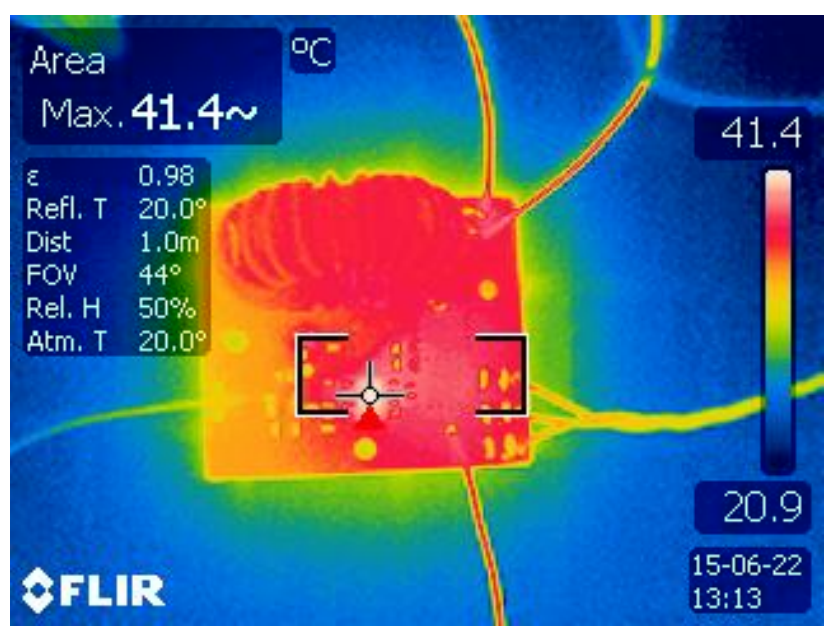

Fig. 4. Thermal picture at maximum power dissipation. 


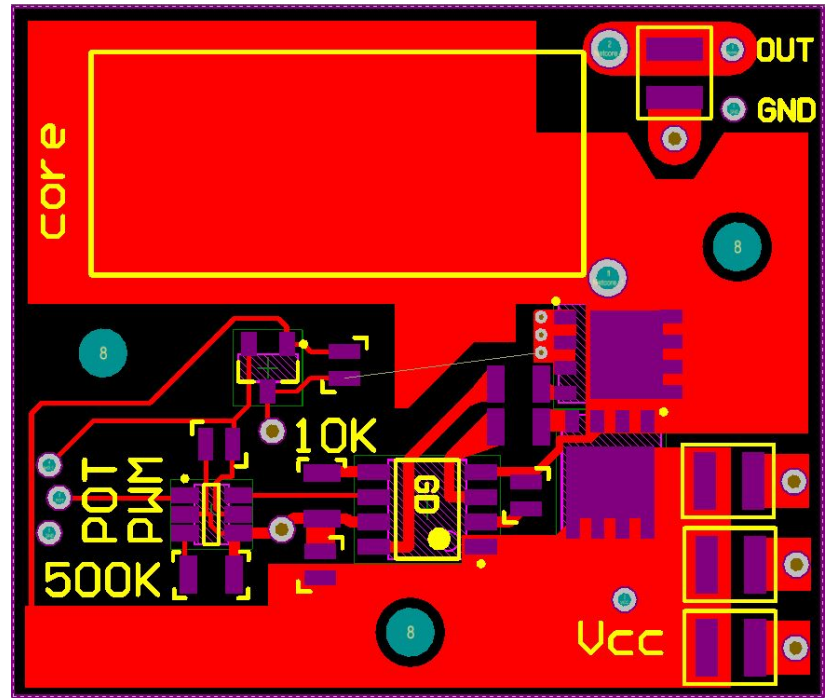

Fig. 5. Final Printed Circuit Board (PCB)

\section{A. Efficiency}

The efficiency of the circuit has been measured at differing duty cycles and with different ohmic loads. These measurements can be seen in Fig. 6. As previously mentioned the alternator winding resistance is estimated to be $2 \Omega$, which means that the actual efficiency of the ergometer in use should be slightly better than or close to the measurements at $2.5 \Omega$ load.

The measurements shows an efficiency of above the targeted $85 \%$, as soon as a duty cycle of $20 \%$ is reached. This threshold of $20 \%$ duty cycle is acceptable due to the relatively low output at this stage.

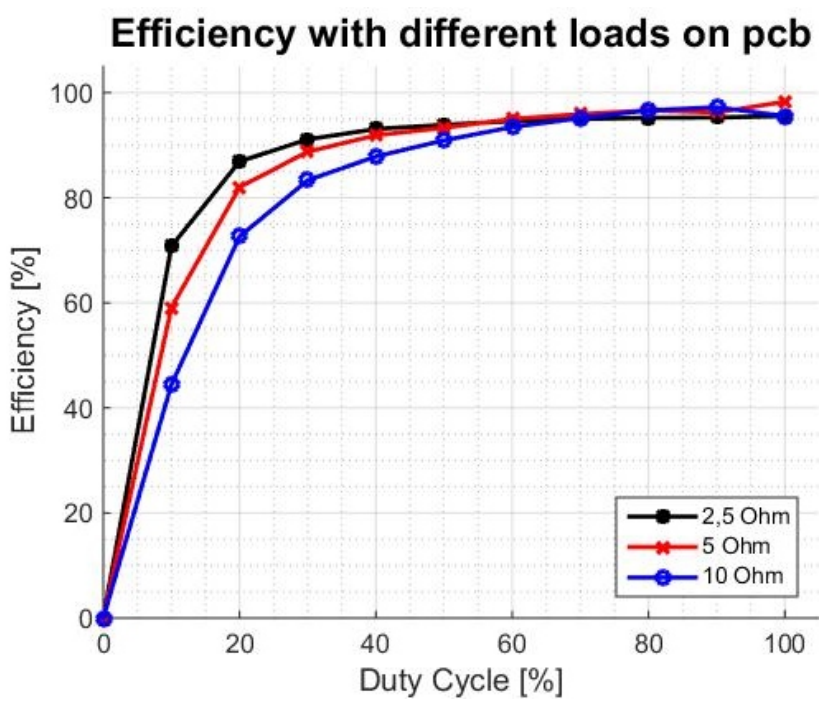

Fig. 6. Effeciency at different loads

\section{B. Ripple}

The output ripple was measured with a load of $2.5 \Omega$ at a $50 \%$ duty cycle, resulting in a peak-peak ripple of $140 \mathrm{mV}$ as seen in Fig. 7, which is equivalent to $56 \mathrm{~mA}$ peak-peak current ripple. At max output the current ripple is:

$$
\frac{56 m A}{4.8 A} \%=1.16 \%
$$

This output ripple is well below our initial goal of a $10 \%$ ripple.

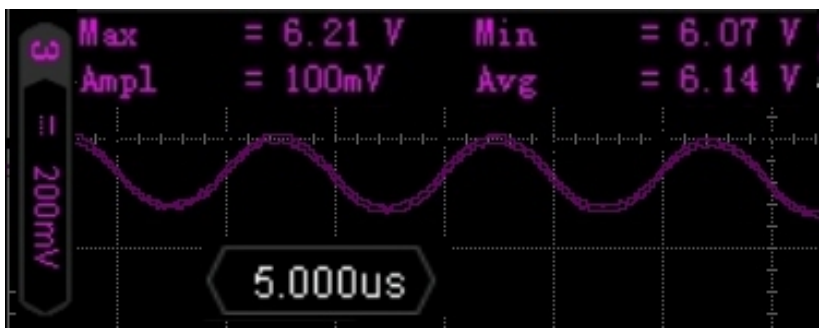

Fig. 7. Output ripple at $50 \%$ duty cycle with $2.5 \Omega$

\section{Emulation}

To emulate the kayak the converter has to react much faster than a human can react (approx. 200ms)[4] for a smooth operation. Fig. 8 shows a rise time well under $60 \mu$ s from duty cycle $30 \%-70 \%$. This states that the converter is fast enough to meet the demand of seamless transition in emulation.

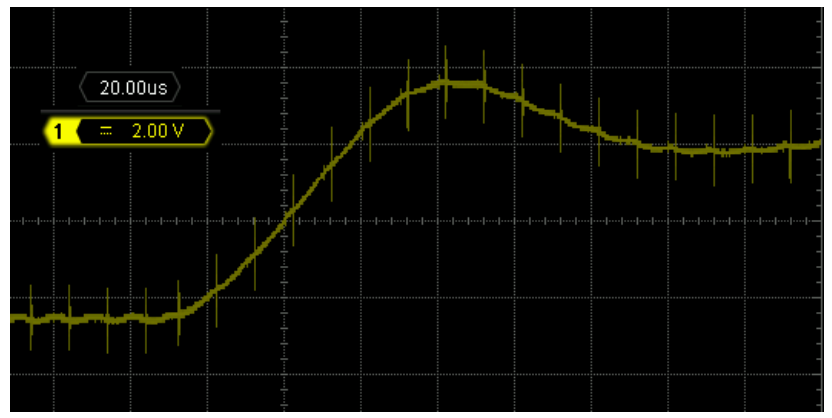

Fig. 8. Rise time output change

We also have to consider how fast the Arduino can adjust the control signal. This can be seen in Fig. 9, where the response time is $25.5 \mathrm{~ms}$ which is fast considering the reaction time of a human as discussed previously. Note that the response time of the converter is added to the total response time, but it is so small that it is negligible. For faster emulation an Arduino Mega or an embedded controller would be the next step.

\section{CONCLUSION}

The purpose of this paper was to create an ergometer with resistance that is given electronically and controlled digitally. We have implemented the alternator and designed a control circuit for controlling the rotor current. We have 


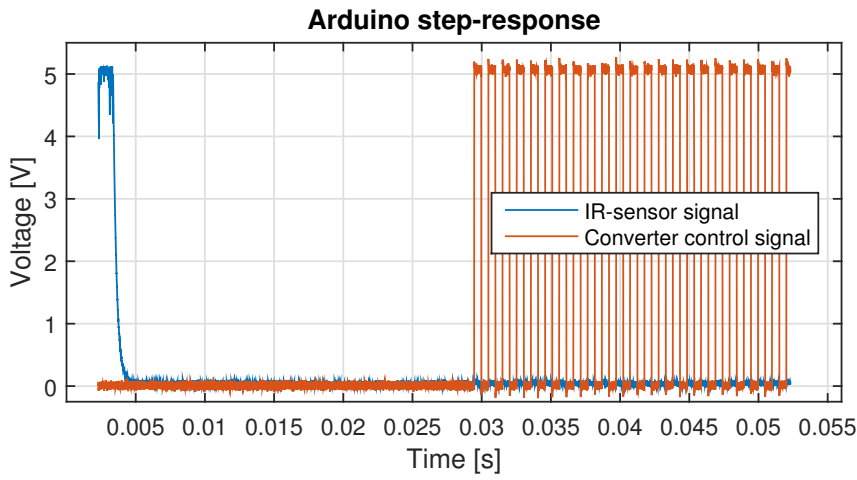

Fig. 9. Arduino control signal change time

then included an Arduino and sensors, and made a platform for implementation of high-end emulation of the kayaking ergometer.

The circuit was designed as a synchronous-rectified buck converter on a PCB. The specifications set for the circuit were all met. The duty cycle of the circuit is controlled by the Arduino, which can be adjusted to any desired system. By perfecting the digital regulator on the Arduino, an accurate emulation of the athlete-kayak-paddle system can be made.

The non-regulated design was presented at the 2015 kayaking world cup and received warmly (Fig. 10). Some rowers stated that it was superior to other ergometers, even in its then non-regulated state.

\section{ACKNOWLEDGEMENT}

The authors would like to thank the staff of Skylab DTU, for helping with constructing the mechanical parts of the project. Special thanks to Dansprint ApS for supplying the kayaking ergometer.

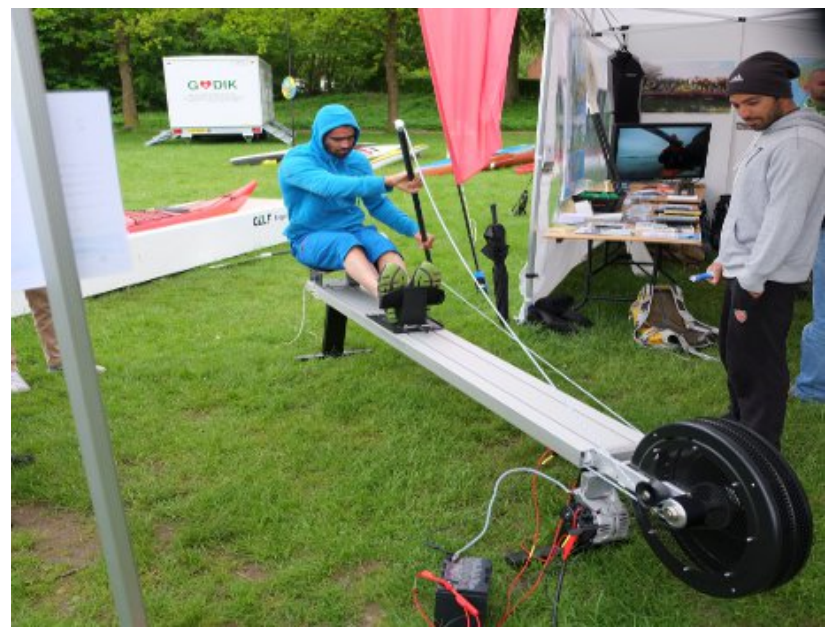

Fig. 10. Professional athlete testing our ergometer at the 2015 Kayaking World Cup.

\section{REFERENCES}

[1] M. Begon, O. Mourasse, and P. Lacouture, "A method of providing accurate velocity feedback of performance on an instrumented kayak ergometer," Sports Engineering, vol. 11, no. 2, pp. 57-65, 2009.

[2] N. Mohan, Power electronics: a first course, 1st ed. Wiley, 2012, ch. 3.

[3] R. Ivankovic, J. Cros, M. T. Kakhki, C. a. Martins, and P. Viarouge, New Advances in Vehicular Technology and Automotive Engineering, 1st ed. InTech, 2012, ch. 6.

[4] M. I. Posner, "Timing the Brain: Mental Chronometry as a Tool in Neuroscience," PLoS Biology 3.2, 2005.

[5] K. Lindberg-Poulsen, M. a. E. Andersen, A. Knott, and T. Andersen, "Energy harvesting from an exercise bike using a switch-mode converter controlled generator," 2010 IEEE International Conference on Sustainable Energy Technologies, ICSET 2010, 2010.

[6] W. L. Soong and N. Ertugrul, "Inverterless high-power interior permanent-magnet automotive alternator," IEEE Transactions on Industry Applications, vol. 40, no. 4, pp. 1083-1091, 2004.

[7] R. Strzelecki, M. Jarnut, and G. Benysek, "Exercise bike powered electric generator for fitness club appliances," 2007 European Conference on Power Electronics and Applications, EPE, 2007. 